\title{
Identifikasi Jiwa Kewirausahaan pada Pemilik Elisabeth Max di Semarang
}

\author{
Vonnie Jane Marsellina; Y. Sugiharto \\ email: kelik.sugiharto@gmail.com \\ Program Studi Manajemen Fakultas Ekonomi Dan Bisnis \\ Universitas Katolik Soegijapranata
}

\begin{abstract}
The objective of this research is to identify the entrepreneurial spirit of Elisabeth Max owner based on Meredith's theory of entrepreneurship. In this research, there were 6 respondents. The sampling technique use is purposive sampling, namely sampling by certain requirements or judgments. In this research, it shoud be studied quantatively by likert scale. Based on the study, it was conclude that the owner was included as a self confidence person, task and result oriented, risk taker, leader spirit, original, and future oriented.
\end{abstract}

Keywords: entrepreuneurship, spirit of entrepreneurship.

\section{PENDAHULUAN}

\section{Latar Belakang Masalah}

Ada tokoh seorang kewirausahaan bernama Geoffrey G Meredith, beliau adalah seorang Direktur dari Financial Management Research Center, University of New England, Australia. Menurut Meredith (1996:3) berwirausaha berarti memadukan perwatakan pribadi, keuangan dan sumber daya. Berwirausaha merupakan salah satu pekerjaan yang harus bersifat fleksibel, imajinatif, mampu merencanakan, berani mengambil resiko, mengambil keputusan dan tindakantindakan agar tujuan dapat tercapai.

Menurut Drucker (dalam Suryana 2013:10) kewirausahaan adalah kemampuan untuk menciptakan sesuatu yang baru dan berbeda. Kemampuan tersebut merujuk pada seseorang yang memiliki jiwa kewirausahaan atau ciri-ciri sebagai wirausaha. Meredith mengemukakan ciri jiwa kewirausahaan, sebagai berikut : percaya diri, berorientasikan tugas dan hasil, pengambil risiko, berjiwa pemimpin, keorisinilan, dan berorientasi ke masa depan. 
Banyak para ahli yang mengemukakan karakteristik kewirausahaan dengan konsep yang berbeda-beda, diantaranya : Menurut Kathleen L. Hawkins \& Peter A. Turla (1986) dalam Suryana (2013:47) pola tingkah laku kewirausahaan tersebut tergambar dalam perilaku dan kemampuan, sebagai berikut : kepribadian, aspek ini bisa diamati dari segi kreatiVitas, disiplin diri, kepercayaan diri, keberanian menghadapi risiko, memiliki dorongan dan kemauan kuat; hubungan, dapat dilihat dari indikator komunikasi dan hubungan ntarpersonal, kepemimpinan dan manajemen; pemasaran, meliputi kemampuan dalam menentukan produk dan harga, periklanan dan promosi; keahlian dalam mengatur, diwujudkan dalam bentuk penentuan tujuan, perencanaan, penjadwalan serta pengaturan pribadi; dan keuangan, indikatornya adalah sikap dan cara mengatur uang.

Keberhasilan yang diraih oleh seorang wirausaha sangat bergantung dari beberapa faktor yaitu kemauan, kemampuan, peluang dan kesempatan. Penggunaan teori ciri jiwa kewirausahaan menurut Meredith (1996), dikarenakan teori tersebut menunjukkan secara spesifik sifat yang harus dimiliki seseorang untuk menjadi wirausaha, teori ini lebih lengkap dibandingkan teori beberapa ahli yang lain. Teori tersebut juga cukup sederhana untuk dipahami oleh pemilik maupun karyawan, karena pola pikir yang digunakan adalah bahwa untuk menjadi seorang wirausaha diperlukan semua ciri-ciri kewirausahaan tersebut. Apabila sifat yang dimiliki masih sedikit kemungkinan belum bisa menjadi wirausaha yang sukses. Kemudahan pola pikir teori tersebut menjadi keunggulan dari teori Meredith sehingga peneliti menggunakan teori ini.

Masyarakat saat ini menyukai produk-produk fashion yang menarik dan berkualitas bagus. Produk fashion khususnya wanita adalah jenis fashion yang populer dan banyak dicari, maka tidak mengherankan banyak pengrajin bisnis yang menjual produk handmade lokal. Produk handmade lokal yang dibuat biasanya mulai dari baju, tas, sepatu dan aksesoris. Sepatu merupakan fashion yang sudah melekat untuk kegiatan sehari- hari, seperti untuk berpergian kekantor, kuliah dikampus, atau hanya sekedar jalan-jalan di pusat perbelanjaan. 
Tanpa disadari sepatu telah dianggap oleh sebagian masyarakat sebagai gaya hidup.

Salah satu usaha handmade lokal adalah ElisabethMax, yang terletak di jalan Bukit Emerald Blok A6-138B, Semarang. Usaha ini dimiliki oleh ibu Vienna Arrienda Wibowo dan didirikan pada tahun 2009. Bisnis hanmade bermula karena kecintaan pemilik pada sepatu dan ingin membuka usaha tersebut. Di dalam usahanya untuk bagian kepala produksi, bagian keuangan dan bagian pemasaran dipegang sendiri oleh pemilik.

ElisabethMax memiliki karyawan berjumlah 5 orang. Awal memulai bisnis ini hanya memproduksi 10 unit sepatu, karena menurut beliau produk handmade lokal peminatnya belum terlalu banyak sehingga beliau hanya memproduksi dengan jumlah tersebut. Seiring berjalannya waktu merek ElisabethMax mulai dikenal beberapa orang, sehingga perkembangan produksinya meningkat yang awalnya hanya 10 unit sekarang sudah mencapai 15-20 unit.

Adapun alasan memilih ElisabethMax sebagai objek penelitian, dikarenakan dalam menjalankan usahanya pemilik mampu mengembangkan dan memajukan usahanya hingga saat ini. Hal ini membuat peneliti tertarik untuk lebih mengenali jiwa kewirausahaan yang dimiliki lbu Vienna Arrienda Wibowo.

\section{Rumusan Masalah}

Berdasarkan latar belakang diatas, maka perumusan masalah dalam penelitian ini adalah : "Bagaimana identifikasi jiwa kewirausahaan pada pemilik Elisabeth Max menurut teori dari Geoffrey G. Meredith ?"

\section{Tujuan Penelitian}

Tujuan dari penelitian ini adalah untuk mengidentifikasi jiwa kewirausahaan pemilik ElisabethMax menurut teori yang dikemukakan oleh Geoffrey G. Meredith. 


\section{LANDASAN TEORI}

\section{Kewirausahaan}

Kewirausahaan adalah suatu ilmu yang mempelajari tentang nilai, kemampuan, dan perilaku seseorang dalam menghadapi tantangan hidup dan cara memperoleh peluang dengan berbagai risiko yang mungkin dihadapinya (Suryana, 2013). Menurut Thomas W. Zimmerer (dalam Suryana 2013:5) bahwa kewirausahaan merupakan proses penerapan kreativitas dan inovasi untuk memecahkan masalah dan mencari peluang yang dihadapi setiap orang dalam setiap hari. Drucker (1994) (dalam Suryana 2013) mengemukakan konsep kewirausahaan merujuk pada sifat, watak, dan ciri-ciri yang melekat pada seseorang yang mempunyai kemauan keras untuk mewujudkan gagasan inovatif ke dalam dunia usaha yang nyata dan dapat mengembangkannya dengan tangguh. Sedangkan menurut Meredith (1996:9) berwirausaha berarti memadukan perwatakan pribadi, keuangan, dan sumber daya. Berwirausaha merupakan suatu pekerjaan atau karier yang harus bersifat fleksibel dan imajinatif, mampu merencanakan, mengambil risiko, keputusan, dan tindakan untuk mencapai tujuan.

\section{Jiwa Kewirausahaan}

Jiwa kewirausahaan adalah faktor yang mendorong seseorang untuk melakukan sesuatu perbuatan atau kegiatan tertentu, sehingga jiwa kewirausahaan dapat diartikan sebagai pendorong perilaku seseorang. Meredith (1996) mengemukakan ciri-ciri jiwa kewirausahaan yaitu :

\section{Percaya diri}

Seseorang yang mempunyai kepercayaan diri, akan selalu memiliki keyakinan, tidak bergantung pada orang lain, indiVidualitas, dan optimisme. Orang yang memiliki kepercayaan diri akan mempunyai kemampuan untuk bekerja sendiri dalam mengorganisasikan, mengawasi, dan meraih kesuksesan (Suryana, 2013). 


\section{Berorientasikan tugas dan hasil}

Seorang wirausahawan yang berorientasikan pada tugas dan hasil memiliki watak kebutuhan akan prestasi, berorientasi laba, tekun dan tabah, tekad kerja keras, mempunyai dorongan yang kuat, energik, dan inisiatif.

\section{Pengambil risiko}

Memiliki kemampuan dalam mengambil sebuah risiko dan menyukai tantangan. Wirausahawan setiap tantangan harus dihadapi penuh dengan perhitungan. Seseorang yang memiliki kepercayaan diri yang tinggi relatif mampu menghadapi dan menyelesaikan masalah tanpa menunggu bantuan orang lain.

\section{Kepemimpinan}

Sifat kepemimpinan memang ada dalam diri masing-masing indiVidu. Seorang wirausahawan yang berhasil selalu memiliki sifat kepemimpinan, kepeloporan, dan keteladanan. IndiVidu tersebut ingin bergaul untuk mencari peluang dan terbuka terhadap kritik serta saran, yang artinya kritik dan saran tersebut dijadikan sebagai peluang bukan suatu ketersinggungan (Suryana 2013).

\section{Keorisinilan}

Wirausahawan yang inovatif adalah orang yang kreatif. Sebagai seorang wirausaha mereka harus mempunyai ide kreatif untuk keberhasilan usahanya, yang dimaksud orisinil disini adalah tidak hanya ikut ide orang lain, tetapi memiliki pendapat sendiri serta kemampuan untuk melaksanakan sesuatu dengan ide yang dimiliki.

6. Berorientasi ke masa depan

Seseorang yang berorientasi ke masa depan adalah orang yang memiliki perspektif dan pandangan ke depan. Karena memiliki pandangan ke depan maka indiVidu tersebut selalu berusaha, berkarsa, dan berkarya. Meskipun terdapat risiko yang mungkin terjadi indiVidu tersebut tetap tabah untuk mencari peluang dan tantangan demi pembaruan masa depan (Suryana 2013). Dari uraian tersebut, dapat disimpulkan bahwa seorang wirausaha paling tidak harus mempunyai beberapa sifat dari keenam ciri-ciri diatas. Walaupun tidak semuanya 
dapat terpenuhi dengan baik, namun jika seseorang memiliki sifat-sifat yang disebutkan, maka kemungkinan seorang wirausaha tersebut berhasil menjadi wirausaha yang sukses.

\section{Fungsi Wirausahawan}

Ada dua fungsi dan peran wirausahawan (Suryana,2013), yaitu :

\section{Fungsi Makro}

Wirausahawan berperan didalam ekonomi nasional sebagai penggerak, pengendali dan pemacu perekonomian dalam suatu negara. Wirausahawan berfungsi sebagai pencipta inVestasi baru, pembentuk modal baru, menghasilkan lapangan pekerjaan baru, meningkatkan ekspor, menciptakan produktiVitas, mendorong terjadinya suatu pertumbuhan ekonomi mengurangi kesenjangan sosial dan meningkatkan kesejahteraan.

\section{Fungsi Mikro}

Fungsi wirausahawan dalam perusahaan adalah sebagai penanggung risiko dan ketidakpastian, mengombinasikan sumber-sumber ke dalam cara yang baru dan berbeda, menciptakan nilai tambah, menciptakan usaha-usaha baru, dan sebagai pencipta peluang-peluang baru.

\section{Kerangka Pikir}

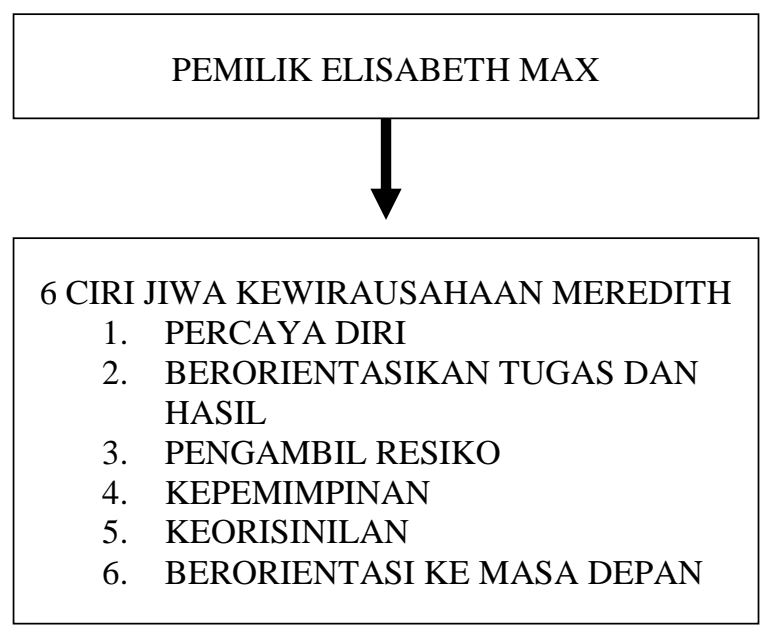

Gambar 1. Kerangka Pikir Penelitian 


\section{Definisi Operasional}

1. Percaya diri. Wirausaha memiliki percaya diri yang kuat, memiliki keyakinan, ketidaktergantungan, sikap indiVidualitas, dan optimisme. Pemilik ElisabethMax membuat keputusan tanpa menunggu dari orang lain, karena menurut beliau pendapat setiap orang akan berbeda-beda yang hanya akan membuatnya bingung. Indikator dalam penelitian ini meliputi : Keyakinan. Pemilik Elisabeth Max; Ketidaktergantungan; Individualitas; Optimisme.

2. Berorientasikan tugas dan hasil. Seorang wirausaha memiliki kebutuhan akan prestasi. Hal tersebut dapat diwujudkan dengan kerja keras didalam menjalankan usahanya dengan sungguh-sungguh. Indikator dalam penelitian ini meliputi : kebutuhan akan prestasi. Berorientasi laba. Ketekunan dan ketabahan. Tekad kerja keras. Mempunyai dorongan kuat. Energitic semangat yang tinggi dan tidak mudah menyerah. Inisiatif.

3. Pengambil risiko. Seorang wirausaha yang memiliki jiwa kewirausahaan biasanya memiliki kemampuan dalam mengambil keputusan dan menyukai tantangan yang sukar tetapi dapat dicapai. Pemilik ElisabethMax percaya bahwa tantangan tersebut akan memberikan pengalaman baru guna mengevaluasi usahanya lebih baik lagi. Indikator dalam penelitian ini meliputi: Kemampuan mengambil risiko. Suka pada tantangan.

4. Kepemimpinan. Merupakan sebuah proses dimana seorang wirausahawan berlaku sebagai pemimpin, menjadi teladan yang baik, tidak mudah emosional, dan menerima kritik serta saran untuk keberlangsungan usahanya. Indikator dalam penelitian ini meliputi : Bertingkah laku sebagai pemimpin. Dapat bergaul dengan orang lain.

5. Keorisinilan. Seseorang yang memiliki jiwa kewirausahaan pasti akan mampu untuk berpikir kreatif dan inoVatif. Ide-ide yang dihasilkan akan selalu menyesuaikan dengan situasi usaha yang terus berkembang. Sifat orisinil disini, indiVidu tersebut tidak hanya bergantung pada orang lain tetapi memiliki pendapat sendiri dan ada kemampuan ide yang orisinil untuk melaksanakan 
sesuatu. Indikator dalam penelitian ini meliputi : Inovatif dan kreatif. Fleksibel. Punya banyak sumber. Serba bisa. Mengetahui banyak.

6. Berorientasi pada masa depan. Gambaran akan masa depan harus ada dan perlu diraih oleh setiap wirausaha dengan upaya-upaya yang maksimal agar usaha yang dijalaninya tetap bertahan di jaman yang semakin global. Indikator dalam penelitian ini meliputi :pandangan ke depan perseptif. Pemilik ElisabethMax memiliki pandangan yang jelas untuk ke masa depan terkait usaha-nya (Contoh : Ingin membuka toko).

\section{METODOLOGI PENELITIAN}

Obyek penelitian ini adalah pemilik ElisabethMax yang beralamat di Jalan Bukit Emerald blok A6 - 138B, Semarang. Populasi adalah wilayah generalisasi yang terdiri atas obyek yang mempunyai kualitas dan karakteristik tertentu yang ditetapkan oleh peneliti untuk dipelajari dan kemudian ditarik kesimpulannya. Sampel adalah bagian dari jumlah dan karakteristik yang dimiliki oleh populasi tersebut (Sugiyono 2012). Karena kesimpulan dari sampel dapat diberlakukan bagi populasi maka sampel diharuskan bersifat representatif (mewakili). Adapun populasi dari penelitian ini adalah pemilik Elisabeth Max yaitu ibu Vienna Arrienda Wibowo dan karyawan yang sudah lama bekerja selama lebih dari 3 tahun (dibagian divisi yang sama yaitu produksi)

Dalam penelitian ini digunakan teknik sampling yang digunakan adalah purposive sampling. Menurut Sugiyono (2012:124), purposive sampling merupakan teknik pengambilan sampel namun dengan menggunakan syarat atau pertimbangan tertentu. Adapun pertimbangan atau syarat yang diperlukan adalah pemilik usaha, dan 3 orang karyawan dari 5 orang karyawan yang telah bekerja minimal selama 3 tahun pada ElisabethMax.

Data yang akan digunakan dalam penelitian ini adalah data primer. Data primer merupakan data yang didapat secara langsung dari sumber data kepada pengumpul data (Sugiyono 2012). Data primer yang diperoleh didapat dari pemilik usaha ElisabethMax dan 3 orang karyawan. Karyawan yang dipilih 
sebagai responden dalam penelitian ini ada dalam satu divisi yang sama, sehingga informasi yang akan didapatkan peneliti tidak jauh berbeda. Oleh karena itu, pertanyaan yang akan diberikan ada pada indikator-indikator yang sama dan tidak memberikan pertanyaan mengenai indikator-indikator yang tidak diketahui 3 orang karyawan tersebut. Metode pengumpulan data yang digunakan dalam penelitian ini adalah dengan menggunakan kuesioner.

Kuesioner adalah daftar pertanyaan atau pernyataan tertulis yang telah disusun kepada responden untuk dijawabnya (Sugiyono 2012:199). Data kualitatif yang diperoleh melalui kuesioner kemudian diolah secara kuantitatif menggunakan skala likert.

Pemberian skor untuk tiap kategori jawaban adalah sebagai berikut :
a. Sangat Setuju (SS)
dengan skor 5
b. Setuju (S)
dengan skor 4
c. $\operatorname{Netral}(\mathrm{N})$
dengan skor 3
d. Tidak Setuju (TS)
dengan skor 2
e. Sangat Tidak Setuju (STS)
dengan skor 1

Teknik analisis yang digunakan dalam penelitian ini adalah analisis statistik deskriptif. Analisis statistik deskriptif adalah analisis statistik yang digunakan untuk menganalisis data dengan cara mendeskripsikan atau menggambarkan sebagaimana adanya tanpa bermaksud membuat kesimpulan yang berlaku untuk umum atau generalisasi (Sugiyono, 2012). Data yang diperoleh akan diidentifikasikan dengan teori Geoffrey G. Meredith terhadap pengusaha handmade ElisabethMax. Langkah-langkah teknik analisis data yang digunakan dalam penelitian ini sebagai berikut : Melakukan penyebaran kuesioner kepada 1 pemilik dan 3 orang karyawan., Menentukan kategori Variabel. Dalam menentukan kategori Variabel, dalam teknik analisis deskriptif alat ukur yang digunakan adalah rentang skala. 
JEMAP : Jurnal Ekonomi, Manajemen, Akuntansi dan Perpajakan

Tabel 1 Rentang Skala Kategori Penilaian

\begin{tabular}{ccccccc}
\hline $\begin{array}{c}\text { Rentang } \\
\text { Skala }\end{array}$ & $\begin{array}{c}\text { Percaya } \\
\text { Diri }\end{array}$ & $\begin{array}{c}\text { Berorientasi } \\
\text { pada tugas dan } \\
\text { hasil }\end{array}$ & $\begin{array}{c}\text { Pengambil } \\
\text { Risiko }\end{array}$ & Kepemimpinan & Keorisinilan & $\begin{array}{c}\text { Berorientasi } \\
\text { ke masa depan }\end{array}$ \\
\hline \hline $1,00-3,00$ & Rendah & Rendah & Rendah & Rendah & Rendah & Rendah \\
\hline $3,01-5,00$ & Tinggi & Tinggi & Tinggi & Tinggi & Tinggi & Tinggi \\
\hline
\end{tabular}

\section{HASIL ANALISIS DAN PEMBAHASAN}

\section{Gambaran Umum}

Elisabeth Max merupakan salah satu usaha handmade lokal yang didirikan pada tahun 2009. Pendiri usaha ini yaitu Ibu Vienna Arrienda Wibowo, usaha ini didirikan karena kecintaan beliau pada sepatu. Usaha ini berlokasi di Jalan Bukit Emerald blok A6 - 138 B, Semarang. Produk-produk handmade yang ditawarkan seperti high heels, flat shoes, sandal, sepatu dan wedges. Pada awal mendirikan usaha, pemilik Elisabeth Max hanya memproduksi 10 unit pasang sepatu saja, lama kelamaan telah meningkat menjadi 15-20 unit.

Sedangkan untuk struktur organisasi Elisabeth Max adalah sebagai berikut :

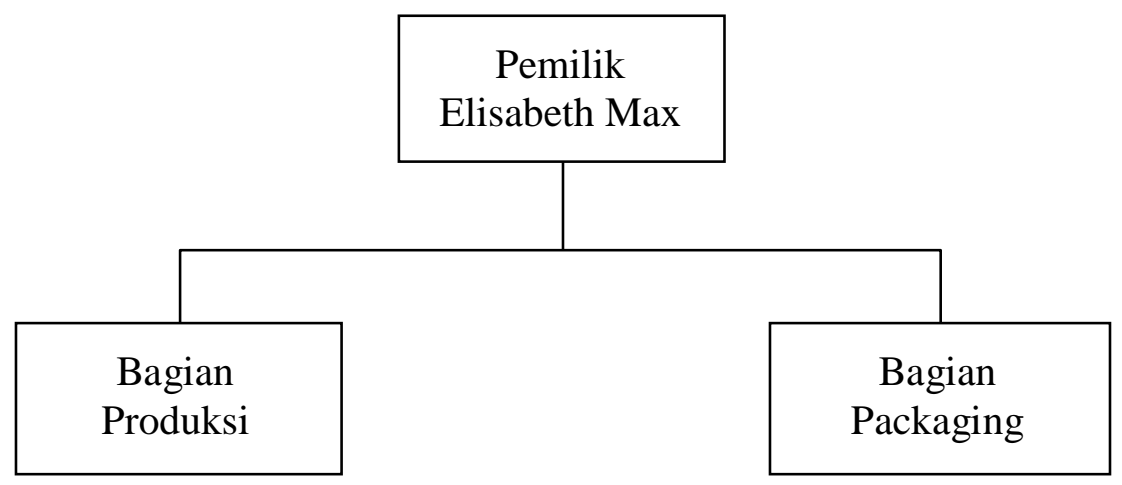

Keterangan dari masing-masing individu yang terdapat dalam organisasi :

1. Pemilik. Pemilik memiliki tugas untuk mengatur dan mengawasi keseluruhan proses produksi hingga barang sampai ditangan konsumen. Sebagai pemimpin 
tentunya pemilik juga memiliki tugas untuk mengeValuasi kinerja karyawan agar usahanya dapat mencapai kesuksesan.

2. Bagian Produksi. Karyawan yang berada dibagian produksi adalah lulusan SMA dan SMP, bertugas untuk melakukan proses produksi produk-produk handmade hingga selesai.

3. Bagian Packaging. Karyawan yang berada dibagian packaging adalah lulusan SMA, bertugas untuk melalukan packaging ke dalam kardus sepatu yang siap untuk dijual.

\section{Gambaran Umum Responden}

Penelitian ini dilakukan dengan cara membagikan kuesioner kepada pemilik ElisabethMax dan 3 orang karyawan dibagian produksi semua. Identitas responden berdasarkan nama, usia, lama bekerja, jenis kelamin dan pendidikan.

Tabel 2 Identitas Responden

\begin{tabular}{cccccccc}
\hline \multirow{2}{*}{ Responden } & \multirow{2}{*}{ Nama } & \multirow{2}{*}{ Usia } & \multicolumn{2}{c}{ Lama } & \multirow{2}{*}{ Jenis } & \multirow{2}{*}{ Pendidikan } \\
& & & Usaha & Bekerja & Kelamin & \\
\hline \hline Pemilik & Vienna Arrienda & 28 th & 7 th & - & P & S.E \\
\hline Karyawan 1 & Udin Fajar & 30 th & - & 4 th & L & SMA \\
\hline Karyawan 2 & Saputra & 29 th & - & 4 th & L & SMA \\
\hline Karyawan 3 & Arif Wibowo & 27 th & - & 3 th & L & SMP \\
\hline
\end{tabular}

Sumber : Data Primer yang diolah (2017)

\section{Hasil Analisis dan Pembahasan}

Pada bagian ini akan dianalisis mengenai keenam ciri jiwa kewirausahaan menurut Geoffrey G. Meredith yaitu percaya diri, berorientasikan tugas dan hasil, pengambil risiko, kepemimpinan, keorisinilan, dan berorientasi ke masa depan. Tabel-tabel berikut akan menunjukkan penilaian responden terhadap ciri jiwa kewirausahaan. 


\section{Percaya Diri}

Kemampuan seorang wirausaha pemilik ElisabethMax pada Variabel percaya diri dengan indikator keyakinan, ketidaktergantungan, indiVidualitas, dan optimisme dengan melakukan pembagian kuesioner kepada pemilik dan karyawan, dengan hasil sebagai berikut :

Tabel 3 Tanggapan Pemilik atas ciri jiwa kewirausahaan - Percaya Diri

\begin{tabular}{lllllllllllll} 
& & & SS & \multicolumn{1}{c}{ S } & & N & & TS & STS & Total \\
\cline { 2 - 8 } Percaya diri & F & 5 & F & 4 & F & 3 & F & 2 & F & 1 & Score & Ket
\end{tabular}

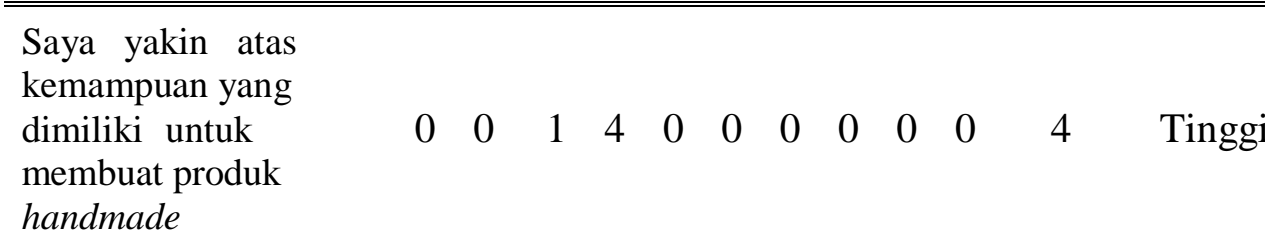

Saya tidak

tergantung pada

$\begin{array}{llllllllllllll}\text { orang lain dalam } & 1 & 5 & 0 & 0 & 0 & 0 & 0 & 0 & 0 & 0 & 5 & \text { Tinggi }\end{array}$ setiap mengambilan

keputusan

\begin{tabular}{llllllllllllllll}
\hline $\begin{array}{l}\text { Saya menjalankan } \\
\text { usaha cenderung } \\
\text { bersifat individu } \\
\text { (mandiri) dalam hal }\end{array}$ & 1 & 5 & 0 & 0 & 0 & 0 & 0 & 0 & 0 & 0 & & 5 & Tinggi \\
mengawasi dan \\
mengorganisasikan \\
proses produksi
\end{tabular}

Saya optimis bahwa usahanya dapat berkembang dan $\begin{array}{lllllllllllll}1 & 5 & 0 & 0 & 0 & 0 & 0 & 0 & 0 & 0 & 5 & \text { Tinggi }\end{array}$ berhasil

Rata - rata score 4,75 Tinggi

Sumber : Data Primer yang diolah (2017)

Berdasarkan Tabel 3 menunjukkan jiwa kewirausahaan berdasarkan Variabel Percaya Diri. Secara keseluruhan maka Variabel percaya diri termasuk dalam kategori tinggi dengan rata- rata skor 4,75. 
JEMAP : Jurnal Ekonomi, Manajemen, Akuntansi dan Perpajakan ISSN : 2622-612X (MediaOnline) | Vol. 1 | No. 2 | Oktober 2018

Berdasarkan pada tabel 4 tersebut, dapat diketahui bahwa ternyata ratarata karyawan untuk Variabel Percaya Diri sebesar 4,62 dan termasuk dalam kategori tinggi.

Tabel 4. Tanggapan Karyawan atas ciri jiwa kewirausahaan - Percaya diri

\begin{tabular}{|c|c|c|c|c|c|c|c|c|c|c|c|c|c|}
\hline \multirow{2}{*}{ Percaya diri } & \multicolumn{2}{|c|}{ SS } & \multicolumn{2}{|c|}{$S$} & \multicolumn{2}{|c|}{$\mathrm{N}$} & \multicolumn{2}{|c|}{ TS } & \multicolumn{2}{|c|}{ STS } & \multirow{2}{*}{$\begin{array}{l}\text { Total } \\
\text { Score }\end{array}$} & \multirow{2}{*}{$\begin{array}{l}\text { Rata } \\
\text {-rata }\end{array}$} & \multirow{2}{*}{ Ket } \\
\hline & $\mathrm{F}$ & 5 & $\mathrm{~F}$ & 4 & $\mathrm{~F}$ & 3 & $\mathrm{~F}$ & 2 & $\mathrm{~F}$ & 1 & & & \\
\hline $\begin{array}{l}\text { Pemilik yakin atas } \\
\text { kemampuan yang } \\
\text { dimiliki untuk membuat } \\
\text { produk } \\
\text { handmade }\end{array}$ & 2 & 10 & 1 & 4 & 0 & 0 & 0 & 0 & 0 & 0 & 14 & 4,6 & Tinggi \\
\hline $\begin{array}{l}\text { Pemilik tidak tergantung } \\
\text { pada } \\
\text { orang lain dalam setiap } \\
\text { pengambilan keputusan }\end{array}$ & 2 & 10 & 1 & 4 & 0 & 0 & 0 & 0 & 0 & 0 & 14 & 4,6 & Tinggi \\
\hline $\begin{array}{l}\text { Pemilik menjalankan } \\
\text { usaha cenderung bersifat } \\
\text { indiVidu (mandiri) dalam } \\
\text { hal mengawasi dan } \\
\text { mengorganisasikan } \\
\text { proses produksi }\end{array}$ & 3 & 15 & 0 & 0 & 0 & 0 & 0 & 0 & 0 & 0 & 15 & 5 & Tinggi \\
\hline $\begin{array}{l}\text { Pemilik optimis bahwa } \\
\text { usahanya dapat } \\
\text { berkembang dan berhasil }\end{array}$ & 1 & 5 & 2 & 8 & 0 & 0 & 0 & 0 & 0 & 0 & 13 & 4,3 & Tinggi \\
\hline Rata - rata score & & & & & & & & & & & & 4,62 & Tinggi \\
\hline
\end{tabular}

Sumber : Data Primer yang diolah (2017)

\section{Beorientasikan Tugas dan Hasil}

Jiwa kewirausahaan pemilik Elisabeth Max pada variabel beorientasi pada tugas dan hasil dengan indikator memiliki kebutuhan akan prestasi, berorientasi laba, ketekunan dan ketabahan, tekad kerja keras, mempunyai dorongan kuat, energitic, dan inisiatif dengan melakukan pembagian kuesioner kepada pemilik dan karyawan, dengan hasil sebagai berikut 
Tabel 5 Tanggapan Pemilik atas ciri jiwa kewirausahaan Berorientasikan Tugas dan Hasil

\begin{tabular}{|c|c|c|c|c|c|c|c|c|c|c|c|c|}
\hline \multirow{2}{*}{$\begin{array}{l}\text { Berorientasikan Tugas dan } \\
\text { Hasil }\end{array}$} & \multicolumn{2}{|c|}{ SS } & \multicolumn{2}{|c|}{$\mathrm{S}$} & \multicolumn{2}{|c|}{$\mathrm{N}$} & \multicolumn{2}{|c|}{ TS } & \multicolumn{2}{|c|}{ STS } & \multirow{2}{*}{$\begin{array}{l}\text { Total } \\
\text { Score }\end{array}$} & \multirow{2}{*}{ Ket } \\
\hline & $\mathrm{F}$ & 5 & $\mathrm{~F}$ & 4 & $\mathrm{~F}$ & 3 & $\mathrm{~F}$ & 2 & $\mathrm{~F}$ & 1 & & \\
\hline $\begin{array}{l}\text { Saya memiliki } \\
\text { kebutuhan akan prestasi } \\
\text { dalam hal penjualan produk }\end{array}$ & 1 & 5 & 0 & 0 & 0 & 0 & 0 & 0 & 0 & 0 & 5 & Tinggi \\
\hline $\begin{array}{l}\text { Saya menjalankan usaha } \\
\text { berfokus pada laba }\end{array}$ & 1 & 5 & 0 & 0 & 0 & 0 & 0 & 0 & 0 & 0 & 5 & Tinggi \\
\hline $\begin{array}{l}\text { Saya dalam setiap } \\
\text { kesempatan berusaha } \\
\text { menambah pelanggan } \\
\text { pelanggan baru }\end{array}$ & 1 & 5 & 0 & 0 & 0 & 0 & 0 & 0 & 0 & 0 & 5 & Tinggi \\
\hline $\begin{array}{l}\text { Saya setiap ada waktu } \\
\text { luang membuat produk } \\
\text { handmade model Terbaru }\end{array}$ & 0 & 0 & 1 & 4 & 0 & 0 & 0 & 0 & 0 & 0 & 4 & Tinggi \\
\hline $\begin{array}{l}\text { Saya dalam hal } \\
\text { mendesain produk belajar } \\
\text { pada internet atau majalah }\end{array}$ & 1 & 5 & 0 & 0 & 0 & 0 & 0 & 0 & 0 & 0 & 5 & Tinggi \\
\hline $\begin{array}{l}\text { Saya memiliki semangat } \\
\text { dan tidak mudah } \\
\text { menyerah menghadapi } \\
\text { masalah }\end{array}$ & 1 & 5 & 0 & 0 & 0 & 0 & 0 & 0 & 0 & 0 & 5 & Tinggi \\
\hline $\begin{array}{l}\text { Saya menjalankan usaha } \\
\text { dengan inisiatif }\end{array}$ & 0 & 0 & 1 & 4 & 0 & 0 & 0 & 0 & 0 & 0 & 4 & Tinggi \\
\hline Rata-rata score & & & & & & & & & & & 4,71 & Tinggi \\
\hline
\end{tabular}

Sumber : Data Primer yang diolah (2017)

Berdasarkan Tabel 6 menunjukkan jiwa kewirausahaan berdasarkan Variabel Berorientasikan Tugas dan Hasil. Secara keseluruhan maka Variabel berorientasikan tugas dan hasil termasuk dalam kategori tinggi dengan rata-rata skor 4,71 . 
Tabel 6 Tanggapan Karyawan atas ciri jiwa

kewirausahaan - Berorientasikan Tugas dan Hasil

\begin{tabular}{|c|c|c|c|c|c|c|c|c|c|c|c|c|c|}
\hline \multirow{2}{*}{$\begin{array}{l}\text { Berorientasikan } \\
\text { Tugas dan Hasil }\end{array}$} & \multicolumn{2}{|c|}{ SS } & \multicolumn{2}{|c|}{$S$} & \multicolumn{2}{|c|}{$\mathrm{N}$} & \multicolumn{2}{|c|}{ TS } & \multicolumn{2}{|c|}{ STS } & \multirow{2}{*}{$\begin{array}{l}\text { Total } \\
\text { Score }\end{array}$} & \multirow{2}{*}{$\begin{array}{l}\text { Rata } \\
\text {-rata }\end{array}$} & \multirow{2}{*}{ Ket } \\
\hline & $\mathrm{F}$ & 5 & $\mathrm{~F}$ & 4 & $\mathrm{~F}$ & 3 & $\mathrm{~F}$ & 2 & $\mathrm{~F}$ & 1 & & & \\
\hline $\begin{array}{l}\text { Pemilik memiliki } \\
\text { kebutuhan akan } \\
\text { prestasi dalam hal } \\
\text { penjualan produk }\end{array}$ & 2 & 10 & 1 & 4 & 0 & 0 & 0 & 0 & 0 & 0 & 14 & 4,6 & Tinggi \\
\hline $\begin{array}{l}\text { Pemilik menjalankan } \\
\text { usaha berfokus pada } \\
\text { laba }\end{array}$ & 2 & 10 & 1 & 4 & 0 & 0 & 0 & 0 & 0 & 0 & 14 & 4,6 & Tinggi \\
\hline $\begin{array}{l}\text { Pemilik dalam setiap } \\
\text { kesempatan selalu } \\
\text { berusaha menambah } \\
\text { pelanggan- pelanggan } \\
\text { baru }\end{array}$ & 2 & 10 & & 4 & 0 & 0 & 0 & 0 & 0 & 0 & 14 & 4,6 & Tinggi \\
\hline $\begin{array}{l}\text { Pemilik setiap ada } \\
\text { waktu luang membuat } \\
\text { produk handmade } \\
\text { model terbaru }\end{array}$ & 2 & 10 & 1 & 4 & 0 & 0 & 0 & 0 & 0 & 0 & 14 & 4,6 & Tinggi \\
\hline $\begin{array}{l}\text { Pemilik dalam hal } \\
\text { mendesain produk } \\
\text { belajar pada internet } \\
\text { atau majalah }\end{array}$ & 2 & 10 & 1 & 4 & 0 & 0 & 0 & 0 & 0 & 0 & 14 & 4,6 & Tinggi \\
\hline $\begin{array}{l}\text { Pemilik memiliki } \\
\text { semangat } \\
\text { dan tidak mudah } \\
\text { menyerah } \\
\text { menghadapi masalah }\end{array}$ & 1 & 5 & 2 & 8 & 0 & 0 & 0 & 0 & 0 & 0 & 13 & 4,3 & Tinggi \\
\hline $\begin{array}{l}\text { Pemilik menjalankan } \\
\text { usaha dengan inisiatif }\end{array}$ & 0 & 0 & 3 & 12 & 0 & 0 & 0 & 0 & 0 & 0 & 12 & 4 & Tinggi \\
\hline Rata - rata score & & & & & & & & & & & & 4,47 & Tinggi \\
\hline
\end{tabular}

Sumber : Data Primer yang diolah (2017)

Berdasarkan pada tabel tersebut, dapat diketahui bahwa ternyata ratarata karyawan untuk Variabel Beorientasikan Tugas dan Hasil sebesar 4,47 dan termasuk dalam kategori tinggi. 


\section{Pengambil Risiko}

Jiwa kewirausahaan pemilik ElisabethMax pada Variabel pengambil risiko dengan indikator kemampuan mengambil risiko dan suka pada tantangan dengan melakukan pembagian kuesioner kepada pemilik dan karyawan, dengan hasil sebagai berikut :

Tabel 7 Tanggapan Pemilik atas ciri jiwa kewirausahaan Pengambil Risiko

\begin{tabular}{|c|c|c|c|c|c|c|c|c|c|c|c|c|}
\hline \multirow{2}{*}{ Pengambil risiko } & \multicolumn{2}{|c|}{ SS } & \multicolumn{2}{|c|}{$S$} & \multicolumn{2}{|c|}{$\mathrm{N}$} & \multicolumn{2}{|c|}{$\mathrm{TS}$} & \multicolumn{2}{|c|}{ STS } & \multirow{2}{*}{$\begin{array}{l}\text { Total } \\
\text { Score }\end{array}$} & \multirow{2}{*}{ Ket } \\
\hline & $\mathrm{F}$ & 5 & $\mathrm{~F}$ & 4 & $\mathrm{~F}$ & 3 & $\mathrm{~F}$ & 2 & $\mathrm{~F}$ & 1 & & \\
\hline $\begin{array}{l}\text { Saya berani } \\
\text { menanggung terjadinya } \\
\text { kerugian } \\
\text { ketidaksesuaian } \\
\text { pemesanan }\end{array}$ & 1 & 5 & 0 & 0 & 0 & 0 & 0 & 0 & 0 & 0 & 5 & Tinggi \\
\hline $\begin{array}{l}\text { Saya menyanggupi } \\
\text { adanya permintaan } \\
\text { pelanggan agar produk } \\
\text { lebih divariasi lagi }\end{array}$ & 0 & 0 & 1 & 4 & 0 & 0 & 0 & 0 & 0 & 0 & 4 & Tinggi \\
\hline Rata - rata score & & & & & & & & & & & 4,50 & Tinggi \\
\hline
\end{tabular}

Sumber : Data Primer yang diolah (2017)

Berdasarkan Tabel 7 terlihat jiwa kewirausahaan berdasarkan ariabel Pengambil Risiko. Secara keseluruhan maka Variabel pengambil risiko termasuk dalam kategori tinggi dengan rata-rata skor 4,5.

Tabel 8 Tanggapan Karyawan atas ciri jiwa kewirausahaan Pengambil risiko

\begin{tabular}{|c|c|c|c|c|c|c|c|c|c|c|c|c|c|}
\hline \multirow{2}{*}{ Pengambil risiko } & \multicolumn{2}{|c|}{ SS } & \multicolumn{2}{|c|}{$S$} & \multicolumn{2}{|c|}{$\mathrm{N}$} & \multicolumn{2}{|c|}{ TS } & \multicolumn{2}{|c|}{ STS } & \multirow{2}{*}{$\begin{array}{l}\text { Total } \\
\text { Score }\end{array}$} & \multirow{2}{*}{$\begin{array}{l}\text { Rata- } \\
\text { rata }\end{array}$} & \multirow{2}{*}{ Ket } \\
\hline & $\mathrm{F}$ & 5 & $\mathrm{~F}$ & 4 & $\mathrm{~F}$ & 3 & $\mathrm{~F}$ & 2 & $\mathrm{~F}$ & 1 & & & \\
\hline $\begin{array}{l}\text { Pemilik berani } \\
\text { menanggung terjadinya } \\
\text { kerugian ketidak } \\
\text { sesuaian pemesanan }\end{array}$ & 1 & 5 & 2 & 8 & 0 & 0 & 0 & 0 & 0 & 0 & 13 & 4,3 & Tinggi \\
\hline
\end{tabular}


Pemilik menyanggupi

adanya permintaan

pelanggan agar produk

$\begin{array}{lllllllllllll}1 & 5 & 2 & 8 & 0 & 0 & 0 & 0 & 0 & 0 & 13 & 4,3 & \text { Tinggi }\end{array}$

lebih divariasi lagi

Rata - rata score

4,30 Tinggi

Sumber : Data Primer yang diolah (2017)

Berdasarkan pada tabel 8 tersebut, dapat diketahui bahwa ternyata rata-rata karyawan untuk Variabel Pengambil Risiko sebesar 4,30 dan termasuk dalam kategori tinggi.

\section{Kepemimpinan}

Sebagai seorang wirausaha harus memiliki sifat kepemimpinan yang baik agar dapat dijadikan panutan. Ibu Vienna mampu mengatur segala aspek yang ada didalam usahanya dengan tepat. Jiwa kewirausahaan pemilik Elisabethmax pada Variabel kepemimpinan dengan indikator bertingkah laku sebagai pemimpin, dapat bergaul dengan orang lain, menanggapi saran-saran dan kritik dengan melakukan pembagian kuesioner kepada pemilik dan karyawan, dengan hasil sebagai berikut :

Tabel 9 Tanggapan Pemilik atas ciri jiwa kewirausahaan - Kepemimpinan

\begin{tabular}{|c|c|c|c|c|c|c|c|c|c|c|c|c|}
\hline \multirow{2}{*}{ Kepemimpinan } & \multicolumn{2}{|c|}{ SS } & \multicolumn{2}{|c|}{$\mathrm{S}$} & \multicolumn{2}{|c|}{$\mathrm{N}$} & \multicolumn{2}{|c|}{ TS } & \multicolumn{2}{|c|}{ STS } & \multirow{2}{*}{$\begin{array}{l}\text { Total } \\
\text { Score }\end{array}$} & \multirow{2}{*}{ Ket } \\
\hline & $\mathrm{F}$ & 5 & $\mathrm{~F}$ & 4 & $\mathrm{~F}$ & 3 & $\mathrm{~F}$ & 2 & $\mathrm{~F}$ & 1 & & \\
\hline $\begin{array}{l}\text { Saya mengawasi dan } \\
\text { Mengontrol proses } \\
\text { produksi }\end{array}$ & 0 & 0 & 1 & 4 & 0 & 0 & 0 & 0 & 0 & 0 & 4 & Tinggi \\
\hline $\begin{array}{l}\text { Saya ramah pada } \\
\text { orang lain agar } \\
\text { pemasaran lebih luas }\end{array}$ & 0 & 0 & 1 & 4 & 0 & 0 & 0 & 0 & 0 & 0 & 4 & Tinggi \\
\hline $\begin{array}{l}\text { Saya menerima saran } \\
\text { dan kritik dari orang } \\
\text { lain untuk desain } \\
\text { produk }\end{array}$ & 0 & 0 & 1 & 4 & 0 & 0 & 0 & 0 & 0 & 0 & 4 & Tinggi \\
\hline Rata - rata score & & & & & & & & & & & 4,00 & Tinggi \\
\hline
\end{tabular}

Sumber : Data Primer yang diolah (2017) 
Berdasarkan Tabel 9 menunjukkan jiwa kewirausahaan berdasarkan Variabel Kepemimpinan. Indikator mengawasi dan mengontrol proses produksi dalam kategori tinggi karena dapat membagi dan mengatur jadwal setiap karyawan dan masalah pengiriman, produksi serta penjahitan dapat terselesaikan dengan baik dengan tugas masing-masing karyawan. Secara keseluruhan maka Variabel kepemimpinan termasuk dalam kategori tinggi dengan rata-rata skor 4,00 .

Tabel 10 Tanggapan Karyawan atas ciri jiwa kewirausahaan Kepemimpinan

\begin{tabular}{|c|c|c|c|c|c|c|c|c|c|c|c|c|c|}
\hline \multirow{2}{*}{ Kepemimpinan } & \multicolumn{2}{|c|}{ SS } & \multicolumn{2}{|c|}{$S$} & \multicolumn{2}{|c|}{$\mathrm{N}$} & \multicolumn{2}{|c|}{ TS } & \multicolumn{2}{|c|}{ STS } & \multirow{2}{*}{$\begin{array}{l}\text { Total } \\
\text { Score }\end{array}$} & \multirow{2}{*}{$\begin{array}{c}\text { Rata- } \\
\text { rata } \\
\text { score } \\
\end{array}$} & \multirow{2}{*}{ Ket } \\
\hline & $\mathrm{F}$ & 5 & $\mathrm{~F}$ & 4 & $\mathrm{~F}$ & 3 & $\mathrm{~F}$ & 2 & $\mathrm{~F}$ & 1 & & & \\
\hline $\begin{array}{l}\text { Pemilik mengawasi } \\
\text { dan mengontrol } \\
\text { proses produksi }\end{array}$ & 2 & 10 & 1 & 4 & 0 & 0 & 0 & 0 & 0 & 0 & 14 & 4,6 & Tinggi \\
\hline $\begin{array}{l}\text { Pemilik ramah pada } \\
\text { orang lain agar } \\
\text { pemasaran lebih luas }\end{array}$ & 2 & 10 & 1 & 4 & 0 & 0 & 0 & 0 & 0 & 0 & 14 & 4,6 & Tinggi \\
\hline $\begin{array}{l}\text { Pemilik menerima } \\
\text { saran dan kritik dari } \\
\text { orang lain untuk } \\
\text { desain produk }\end{array}$ & 2 & 10 & 1 & 4 & 0 & 0 & 0 & 0 & 0 & 0 & 14 & 4,6 & Tinggi \\
\hline Rata - rata score & & & & & & & & & & & & 4,60 & Tinggi \\
\hline
\end{tabular}

Sumber : Data Primer yang diolah (2017)

Berdasarkan pada tabel 10 tersebut, dapat diketahui bahwa ternyata ratarata karyawan untuk Variabel ini sebesar 4,60 dan termasuk dalam kategori tinggi.

\section{Keorisinilan}

Seorang wirausaha, jika ingin usahanya berhasil dituntut harus bisa berpikir kreatif dan inoVatif serta memiliki sikap ketelitian yang cukup tinggi untuk mengantisipasi minimnya kegagalan. Jiwa kewirausahaan pemilik ElisabethMax pada Variabel keorisinilan dengan indikator inoVatif dan kreatif, fleksibel, punya 
banyak sumber, serba bisa, dan mengetahui banyak dengan melakukan pembagian kuesioner kepada pemilik, dan karyawan, dengan hasil sebagai berikut :

Tabel 11 Tanggapan Pemilik atas ciri jiwa kewirausahaan Keorisinilan

\begin{tabular}{|c|c|c|c|c|c|c|c|c|c|c|c|c|}
\hline \multirow{2}{*}{ Keorisinilan } & \multicolumn{2}{|c|}{ SS } & \multicolumn{2}{|c|}{$S$} & \multicolumn{2}{|c|}{$\mathrm{N}$} & \multicolumn{2}{|c|}{ TS } & \multicolumn{2}{|c|}{ STS } & \multirow{2}{*}{$\begin{array}{l}\text { Total } \\
\text { Score }\end{array}$} & \multirow{2}{*}{ Ket } \\
\hline & $\mathrm{F}$ & 5 & $\mathrm{~F}$ & 4 & $\mathrm{~F}$ & 3 & $\mathrm{~F}$ & 2 & $\mathrm{~F}$ & 1 & & \\
\hline $\begin{array}{l}\text { Saya mempunyai ide- } \\
\text { ide kreatif untuk produk } \\
\text { yang dihasilkan }\end{array}$ & 0 & 0 & 1 & 4 & 0 & 0 & 0 & 0 & 0 & 0 & 4 & Tinggi \\
\hline $\begin{array}{l}\text { Saya merupakan } \\
\text { IndiVidu yang mudah } \\
\text { beradaptasi dengan } \\
\text { perkembangan jaman }\end{array}$ & 1 & 5 & 0 & 0 & 0 & 0 & 0 & 0 & 0 & 0 & 5 & Tinggi \\
\hline $\begin{array}{l}\text { Saya berlangganan } \\
\text { majalah fashion untuk } \\
\text { dijadikan kelengkapan } \\
\text { sumber inspirasi }\end{array}$ & 0 & 0 & 1 & 4 & 0 & 0 & 0 & 0 & 0 & 0 & 4 & Tinggi \\
\hline $\begin{array}{l}\text { Saya merupakan } \\
\text { pengusaha serba bisa } \\
\text { dalam hal mendesain } \\
\text { produk handmade } \\
\text { sesuai permintaan }\end{array}$ & 0 & 0 & 1 & 4 & 0 & 0 & 0 & 0 & 0 & 0 & 4 & Tinggi \\
\hline $\begin{array}{l}\text { Saya merupakan } \\
\text { pengusaha yang } \\
\text { mengetahui wawasan } \\
\text { secara umum }\end{array}$ & 0 & 0 & 1 & 4 & 0 & 0 & 0 & 0 & 0 & 0 & 4 & Tinggi \\
\hline Rata - rata score & & & & & & & & & & & 4,20 & Tinggi \\
\hline
\end{tabular}

Sumber : Data Primer yang diolah (2017)

Berdasarkan Tabel 11 menunjukkan jiwa kewirausahaan berdasarkan Variabel Keorisinilan. Secara keseluruhan maka Variabel Keorisinilan termasuk dalam kategori tinggi dengan rata-rata 4,20. 
JEMAP : Jurnal Ekonomi, Manajemen, Akuntansi dan Perpajakan

Tabe1 12 Tanggapan Karyawan atas ciri jiwa kewirausahaan Keorisinilan

\begin{tabular}{|c|c|c|c|c|c|c|c|c|c|c|c|c|c|}
\hline \multirow{2}{*}{ Keorisinilan } & \multicolumn{2}{|c|}{ SS } & \multicolumn{2}{|c|}{ S } & \multicolumn{2}{|c|}{$\mathrm{N}$} & \multicolumn{2}{|c|}{$\mathrm{TS}$} & \multicolumn{2}{|c|}{ STS } & \multirow{2}{*}{$\begin{array}{l}\text { Total } \\
\text { Score }\end{array}$} & \multirow{2}{*}{$\begin{array}{l}\text { Rata } \\
\text {-rata }\end{array}$} & \multirow{2}{*}{ Ket } \\
\hline & $\mathrm{F}$ & 5 & $\mathrm{~F}$ & 4 & $\mathrm{~F}$ & 3 & $\mathrm{~F}$ & 2 & $\mathrm{~F}$ & 1 & & & \\
\hline $\begin{array}{l}\text { Pemilik mempunyai } \\
\text { ide-ide kreatif untuk } \\
\text { produk yang dihasilkan }\end{array}$ & 1 & 5 & 2 & 8 & 0 & 0 & 0 & 0 & 0 & 0 & 13 & 4,3 & Tinggi \\
\hline $\begin{array}{l}\text { Pemilik indiVidu yang } \\
\text { mudah beradaptasi } \\
\text { dengan perkembangan } \\
\text { jaman }\end{array}$ & 1 & 5 & 2 & 8 & 0 & 0 & 0 & 0 & 0 & 0 & 13 & 4,3 & Tinggi \\
\hline $\begin{array}{l}\text { Pemilik berlangganan } \\
\text { majalah fashion untuk } \\
\text { dijadikan kelengkapan } \\
\text { sumber inspirasi }\end{array}$ & 0 & 0 & 3 & 12 & 0 & 0 & 0 & 0 & 0 & 0 & 12 & 4 & Tinggi \\
\hline $\begin{array}{l}\text { Pemilik merupakan } \\
\text { pengusaha serba bisa } \\
\text { dalam hal mendesain } \\
\text { produk handmade } \\
\text { sesuai permintaan }\end{array}$ & 0 & 0 & 3 & 12 & 0 & 0 & 0 & 0 & 0 & 0 & 12 & 4 & Tinggi \\
\hline $\begin{array}{l}\text { Pemilik merupakan } \\
\text { pengusaha yang } \\
\text { mengetahui wawasan } \\
\text { secara umum }\end{array}$ & 0 & 0 & 3 & 12 & 0 & 0 & 0 & 0 & 0 & 0 & 12 & 4 & Tinggi \\
\hline Rata - rata score & & & & & & & & & & & & 4,12 & Tinggi \\
\hline
\end{tabular}

Sumber : Data Primer yang diolah (2017)

Berdasarkan pada tabel 12 tersebut, dapat diketahui bahwa ternyata ratarata karyawan untuk Variabel Keorisinilan sebesar 4,12 dan termasuk dalam kategori tinggi.

Jiwa kewirausahaan pemilik ElisabethMax pada Variabel berorientasi ke masa depan dengan indikator pandangan ke depan perseptif dengan melakukan pembagian kuesioner kepada pemilik dan karyawan, dengan hasil sebagai berikut : 
Tabel 13 Tanggapan Pemilik dan Karyawan atas ciri jiwa kewirausahaan Berorientasi ke masadepan

\begin{tabular}{lcccc}
\hline \multirow{2}{*}{ Keterangan } & \multicolumn{2}{c}{ Pemilik } & \multicolumn{2}{c}{ Karyawan } \\
\cline { 2 - 5 } & Skor & Kategori & Skor & Kategori \\
\hline $\begin{array}{l}\text { Berorientasi ke masa depan } \\
\text { (Memiliki pandangan yang } \\
\text { jelas terkait usaha yang }\end{array}$ & 5,00 & Tinggi & 4,00 & Tinggi \\
\hline Rata - rata score & 5,00 & Tinggi & 4,00 & Tinggi \\
\hline
\end{tabular}

Sumber : Data Primer yang diolah (2017)

Berdasarkan pada tabel 13 tersebut, dapat diketahui bahwa ternyata ratarata pemiik untuk Variabel ini sebesar 5,00 dan rata-rata karyawan untuk Variabel ini sebesar 4,00 dan termasuk dalam kategori tinggi.

Setelah dilakukan analisis pada setiap ciri jiwa kewirausahaan menurut teori Geoffrey G. Meredith, maka untuk melihat hasil rekapitulasinya dilihat dengan tabel berikut ini :

Tabel 14 Hasil Rekapitulasi Keseluruhan

\begin{tabular}{|c|c|c|c|c|}
\hline No & Jiwa Kewirausahaan & Pemilik & Karyawan & Keterangan \\
\hline 1 & Percaya Diri & $\begin{array}{c}\text { Tinggi } \\
4,75\end{array}$ & $\begin{array}{c}\text { Tinggi } \\
4,62\end{array}$ & Tinggi \\
\hline 2 & $\begin{array}{l}\text { Berorientasikan Tugas } \\
\text { dan Hasil }\end{array}$ & $\begin{array}{c}\text { Tinggi } \\
4,71\end{array}$ & $\begin{array}{c}\text { Tinggi } \\
4,47\end{array}$ & Tinggi \\
\hline 3 & Pengambil Risiko & $\begin{array}{c}\text { Tinggi } \\
4,50\end{array}$ & $\begin{array}{c}\text { Tinggi } \\
4,30\end{array}$ & Tinggi \\
\hline 4 & Kepemimpinan & $\begin{array}{l}\text { Tinggi } \\
4,00\end{array}$ & $\begin{array}{c}\text { Tinggi } \\
4,60\end{array}$ & Tinggi \\
\hline 5 & Keorisinilan & $\begin{array}{c}\text { Tinggi } \\
4,20\end{array}$ & $\begin{array}{c}\text { Tinggi } \\
4,12\end{array}$ & Tinggi \\
\hline 6 & $\begin{array}{l}\text { Berorientasi Ke masa } \\
\text { depan }\end{array}$ & $\begin{array}{l}\text { Tinggi } \\
5,00\end{array}$ & $\begin{array}{c}\text { Tinggi } \\
4,00\end{array}$ & Tinggi \\
\hline
\end{tabular}

Sumber : Data Primer yang diolah (2017) 


\section{PENUTUP}

\section{Kesimpulan}

Berdasarkan hasil analisis yang telah dilakukan dapat disimpulkan bahwa identifikasi Jiwa Kewirausahaan Pemilik ElisabethMax menurut teori Geoffrey G. Meredith adalah sebagai berikut Pemilik ElisabethMax termasuk kategori wirausaha yang memiliki kepercayaan diri tinggi. Pemilik ElisabethMax termasuk kategori wirausaha yang berorientasikan tugas dan hasil tinggi. Pemilik ElisabethMax termasuk kategori wirausaha yang berani mengambil risiko tinggi. Pemilik ElisabethMax termasuk kategori wirausaha yang memiliki jiwa kepemimpinan tinggi. pemilik ElisabethMax termasuk kategori wirausaha yang memiliki orisinalitas, dapat berpikir kreatif \& inovatif, fleksibel, punya banyak sumber, serba bisa dan mengetahui banyak tinggi. Pemilik ElisabethMax termasuk kategori wirausaha yang berorientasi pada masa depan tinggi

\section{Saran}

Jiwa Kewirausahaan Pemilik ElisabethMax tinggi, tetapi perlu ditingkatkan dalam hal : Pemimpin sebaiknya lebih berani memasarkan produknya dengan mengikuti pameran karena agar dapat mengembangkan usahanya. Lebih berani menciptakan produk handmade, khususnya dalam hal desain. Hal ini akan mendukung keorisinilan produk yang dihasilkan agar konsumen lebih tertarik dan dapat bersaing dengan produk handmade yang serupa. 


\section{DAFTAR PUSTAKA}

Balqish, Farah. 2015, "Pengaruh Jiwa Kewirausahaan Terhadap Keberhasilan Usaha Distro dikota Bandung 2015 (Studi pada distro yang terdaftar pada Kick di kota Bandung).

Meredith, Geoffrey G. 1996, Kewirausahaan Teori dan Praktek. Jakarta: PT Pustaka Binaman Pressindo.

Sugiyono,2012. Metode Penelitian Pendidikan Pendekatan Kuantitatif, Kualitatif dan $R \& D$. Bandung : Alfabeta.

Suryana, 2013.Kewirausahaan:Kiat dan Proses Menuju Sukses. Jakarta : Salemba Empat.

Susanto, Angelina Vania Budi, 2015. Identifikasi entrepreneurship pengusaha took Angel Game Semarang menurut teori Geoffrey G. Meredith 